\title{
Antonio Núñez de Miranda y los libros para la formación femenina en la Nueva España
}

\author{
Elvia CARREÑo VELÁZQUEZ \\ (Instituto de Investigaciones Filológicas, UNAM)
}

\section{Resumen}

Las bibliotecas conventuales femeninas en la Nueva España develan el modelo cultural al que toda mujer novohispana debía aspirar. Ciertamente, se ha pensado que su formación estaba centrada en los rezos y ritos litúrgicos. Sin embargo en el año 1712 el jesuita Antonio Núñez de Miranda sacó a la luz Distribución de las obras ordinarias y extraordinarias, en donde se indican los libros, los títulos, los autores, las partes y las ediciones que empleaban las mujeres. La obra toma relevancia por ser Núñez de Miranda confesor de Sor Juana Inés de la Cruz y por hallarse en tres acervos femeninos la lista completa de los libros indicados por el autor. Distribución de las obras ordinarias y extraordinarias, en consecuencia, no sólo da el universo literario al que la mujer tenía acceso, sino también su consumo y las características de impresión que los libros poseían como son formatos, grabados y lenguas.

Palabras clave: Libro antiguo; Bibliotecas femeninas; Lectura; Imprenta.

\section{Antonio Núñez de Miranda and the books for women formation in the New Spain}

\section{Abstract}

In New Spain, the female conventual libraries shows the cultural model that all the novohispanic woman has to aspire. Certainly, it has been thought that their education is focused in prayers and liturgical rituals. However in 1712, the jesuit Antonio Núñez de Miranda wrote Distribution of ordinary and 
extraordinary works, where it shows the books, the titles, the authors and the editions, that women used to use. The work becomes relevant because Núñez de Miranda was Sor Juana's confessor and because it has been found in three female collections, the complete list indicated by the autor. Distributions of ordinary and extraordinary works, in consequence, it doesn't give the literacy universe where the woman has access even their consume and the characteristics that books had to have like formats, prints and languages.

Keywords: Old book; Female libraries; Novohispanic reading; Printing house.

\section{Introducción}

Las bibliotecas conventuales femeninas en la Nueva España más que un depósito de libros representan la formación espiritual o el camino hacia la perfección al que toda mujer debía aspirar. En México, durante mucho tiempo, se ha pensado que su formación estaba centrada en los rezos y ritos litúrgicos. Sin embargo, en el año 1712 el jesuita Antonio Núñez de Miranda sacó a la luz Distribución de las obras ordinarias y extraordinarias del día..., ${ }^{1}$ en donde se muestra el compendio bibliográfico al que las religiosas tenían acceso; e incluso Núñez de Miranda además de los títulos y los autores señala las ediciones, las partes y la hora en que debía leerse. La obra toma relevancia por ser Núñez de Miranda confesor de Sor Juana Inés de la Cruz y por hallarse en cinco acervos femeninos la lista completa de los libros indicados por el autor. La multitud de referencias en esta obra se vuelve una línea recta que vislumbra el consumo del libro femenino.

Este trabajo pretende mostrar los libros que las mujeres novohispanas de los siglos xvii y xviii adquirían, así como sus particularidades a partir de tres medios. El primero con el escrito Distribución de las obras ordinarias... de Antonio Núñez de Miranda. El segundo con la consulta de los acervos femeninos que aún existen y son accesibles en México $^{2}$ y el tercero con el

\footnotetext{
${ }^{1} \mathrm{El}$ título completo es Distribucion de las obras ordinarias, y extraordinarias del dia, para hazerlas perfectamente, conforme al estado de las señoras religiosas. Instruida con doze maximas substanciales, para la vida regular, y espiritual que deben seguir dispuestas por el R. P. M. Antonio Nuñez de la sagrada Compañia de Jesus, prefecto que fué de la Illustre Congregacion de la Purissima. Sale a la luz a solicitud y expensas de las señoras religiosas del Convento Real de Jesus Maria. Quienes la dedican a Christo Señor Nuestro Sacramentado, en Mexico, por la viuda de Miguel de Ribera Calderon, 1712.

2 Los acervos consultados son El Convento de San José de Gracia de la ciudad de México con 197 volúmenes; el Convento de Carmelitas Descalzas de San José y Santa Teresa de Puebla de Puebla con 436 obras; los Conventos de Santa Catalina de Siena de la Orden de Santo Domingo de Puebla y Morelia, Michoacán con 772 y 1,142 libros respectivamente y el Colegio de San Ignacio de Loyola de las Vizcaínas de la ciudad de México con 519 volúmenes.
}

Titivillus, ISSN 2387-0915, ISSN-e 2603-9966, 1 (2015), pp. 295-303 
único inventario, hasta el día de hoy identificado de una biblioteca femenina novohispana, a saber la del Convento de Carmelitas Descalzas de San José y Santa Teresa de Puebla.

\section{Mujer y libro}

Las mujeres novohispanas tenían acceso al libro a través de la cultura y la educación que recibían, ciertamente no de forma directa, sino revisada, regulada y autorizada por sus formadores, que eran las maestras, las amigas y, sobre ellas, los confesores o directores espirituales, a quienes el padre de familia confiaba su instrucción. El hogar, los beaterios, los colegios y los conventos fueron los centros de formación femenina y los lugares en donde la sociedad colonial optó por enviar a sus hijas con el propósito de completar su formación, mientras llegaba el momento de tomar matrimonio o la profesión religiosa. Es por ello que obispos, directores espirituales los vigilaban escrupulosamente.

Los trabajos y las pruebas de vida que Dios les imponía a las beatas y monjas junto con las penitencias y mortificaciones, estaban encaminadas a purificar su alma. Éste fue el llamado camino de perfección y era el objetivo principal de la formación femenina novohispana. La búsqueda de Dios a través de este complejo sistema de relaciones se convirtió en un principio fundamental del quehacer místico en el cual los libros se volvieron el instrumento con el que se aprendía, meditaba y alumbraba el camino. Todo ello trajo como consecuencia en la Nueva España el fenómeno del despertar de la espiritualidad femenina en el siglo XVII, que tenía como antecedentes las obras de Santa Teresa de Jesús y Sor María de Ágreda «que fueron los pilares de una renovación espiritual del papel de la mujer dentro de la ortodoxia posttridentina... sermones, panegíricos, crónicas conventuales, biografías de monjas y beatas, cartillas y textos de carácter femenino se multiplicaron en una expresión de intereses y admiración por parte de los hombres». ${ }^{3}$ A partir de entonces en los centros educativos novohispanos -conventos y colegios- el libro estará presente en sus horas para las labores, para tomar sus alimentos, para dormir y para reflexionar.

\section{Libros para la formación femenina}

Antonio Núñez de Miranda creó una literatura para la mujer novohispana a partir del contacto y la convivencia con ellas, e indirectamente hizo una compilación bibliográfica que influyó en los libros que usaron los conventos y

\footnotetext{
${ }^{3}$ Véase Lavrin, Asunción y Rosalva Loreto, ed. Monjas y beatas: la escritura femenina en la espiritualidad barroca novohispana, siglos XVII y XVIII, México, Universidad de las Américas, Archivo General de la Nación, p. 18.
} 
que formaron sus acervos, pues fue el autor más leído y encontrado en los monasterios de México. ${ }^{4}$ Entre sus títulos se halla ${ }^{5}$ su obra póstuma Distribución de las obra ordinarias y extraordinarias del día... que está dividida en dos partes. La primera contiene doce máximas que analizan el proceder, la actitud y las obligaciones de la novicia o de las mujeres dentro de la sociedad. La segunda comprende la instrucción de la religiosa en el convento y abarca cinco apartados: el primero instruye en la doctrina; el segundo trata sobre las reglas, constituciones y costumbres del cenobio; el tercero habla de las vidas ejemplares; el cuarto sobre el coro y el oficio divino y el quinto los ejercicios espirituales. A través de dichos o rimas Núñez de Miranda se dirige a su lectora, a quien no sólo instruye con su discurso sino también educa al recomendarle lecturas, señalándoles desde el autor hasta la parte, indicando, incluso, el tomo, capítulo o parágrafo y el impresor. Como ejemplo transcribimos la siguiente sección que dice:

\section{PRIMERA MÁXIMA}

Antes morir, y padecer todo mal, que hacer pecado mortal

Esta es la primera base, y piedra fundamental del edificio espiritual... y lo aprenderéis... leyendo el texto del Catecismo... del padre Jerónimo Ripalda... y las Explicaciones... del Cardenal Bellarmino, Fray Juan de Santo Tomás, [y] del padre Juan Eusebio [Nieremberg]... de ellos conviene ver las de Sancha y Hermosilla. Aconsejo leerlos por la mañana para meditar su enseñanza. El segundo medio es hacer digno concepto... de la gravedad del pecado mortal. Esto lo alcanzaréis con la gracia de Dios, y por la lección de buenos libros, tales son las obras del padre maestro fray Luis de Granada, el padre Juan Eusebio, en su Temporal, y Eterno, y casi

\footnotetext{
4 Véanse los catálogos bibliográficos del Fondo José Gutiérrez, S. J. de la Biblioteca Eusebio Kino de la Compañía de Jesús de México; asimismo, los de las bibliotecas de los Monasterios de Santa Catalina de Sena de la Orden de Santo Domingo de Puebla y Michoacán, al igual que los de las bibliotecas Nacional de México, Palafoxiana, el Centro de Espiritualidad del Carmen Toluca; de los Seminarios Conciliares de Querétaro, Zacatecas y Puebla; de las Universidades de Michoacán y Guanajuato; del Colegio San Ignacio de Loyola de las Vizcaínas, de la Biblioteca Félix de Jesús Rougier de los Misioneros del Espíritu Santo; así como el de la Biblioteca Francisco de Burgoa en Oaxaca o el del Convento de Carmelitas Descalzas de San José y Santa Teresa de Puebla, entre otros, en donde constatamos que por los menos hay dos títulos de sus obras y más de tres ejemplares de cada uno de ellos.

5 Otras de sus obras son: Cartilla de religiosas; El comulgador penitente; La exposición teórica práctica del libro cuarto del Contempus mundi; La explicación del decreto acerca de la comisión cotidiana; La plática en San Loreño; Los ejercicios de San Ignacio acomodados al estado y profesión religiosa y La vida de Santa Ana.
}

Titivillus, ISSN 2387-0915, ISSN-e 2603-9966, 1 (2015), pp. 295-303 
todos los diarios e instrucciones cristianas... de ellos vale la pena leer los estampados por Orga o por la Real imprenta. ${ }^{6}$

El autor, como es evidente, al citar las obras las trata bajo los rubros temáticos y cuando se refiere a los impresores sólo da su apellido; para la edición o el contenido señala su presentación indicando: «en sentencias», «en tomos» o «en libros», incluso, da la ciudad, cuando especifica su preferencia, como lo apreciamos en el siguiente texto:

A estas doce máximas se pudieran añadir otras muchas... pero por no sobrecargar más vuestra tierna vocación, bastarán las insinuadas, y si os agrada... podéis leer los de Santa Teresa, que en forma de sentencias breves, andan al fin de sus obras, y comentados en dos tomos enteros, que dio a luz para bien de las almas el padre Alonso de Andrade. Los dichos de San Felipe Neri, las Sentencia de Santo Tomás de Aquino, y finalmente los dictámenes del padre Juan Eusebio, que primero se imprimieron sueltos en un cuaderno pequeñito y después, al fin del Contemptus mundi, que enmendado en la traducción... se imprimió en Flandes y, finalmente, se pusieron en sus obras. ${ }^{7}$

El título de la obra que cita de Nieremberg es Los cuatro libros de la imitación de Cristo y menosprecio del mundo, compuesto en latín por el venerable Tomás de Kempis, canónico regular de San Agustín, y traducidos nuevamente en español por el P. Juan Eusebio Nieremberg, de la Compañía de Jesús. Van añadidas de los dictámenes de espíritu y perfección, sacados de las obras del mismo P. Juan Eusebio publicadas en Amberes en la Oficina Plantiniana en 1656.

Por otro lado, Antonio Núñez de Miranda al aludir a los impresos efímeros indica «papeles o papelitos», como lo vemos cuando dice «para la comprensión y meditación de las horas canónicas sugiero la compra de devociones... que corresponden a cada hora... las cuales andan impresos en papelitos $^{8}$ de a diez y seis y traducidos en romance». ${ }^{9}$ En relación con los formatos al hablar de folios dice obra en mayor; para el cuarto, tomo o cuaderno; para el octavo, cuaderno pequeñito y para el diez y seisavo no hace cambios. Sirva como ejemplo el siguiente párrafo:

\footnotetext{
${ }^{6}$ Núñez, Distribución..., pp. 34-6. A partir de esta referencia se ha actualizado la ortografía con el propósito de tener una mejor comprensión de la lectura y se ha puesto entre corchetes las palabras que se consideraron pertinentes para la redacción, lo restante se respetó.

${ }^{7}$ Núñez, Distribución..., p. 38

${ }^{8}$ Entiéndase por papelitos los pliegos sueltos o impresos efímeros.

${ }_{9}$ Véase página 75
} 
Usaréis el libro mayorcito, porque la letra es grande, y no os lastime los ojos, ni quiebre la cabeza... habéis de tener otro pequeñito, que sin dificultad, ni pesadez se pueda traer en un bolsico... los cuadernos en cambio lo podéis leer en grupo. ${ }^{10}$

Para los autores Núñez de Miranda hace una clara distinción, pues cuando habla de europeos da el apellido; esto no sucede con los que escribieron o publicaron en México, de ellos proporciona el nombre completo; así se aprecia en su comentario sobre la práctica de la liturgia que dice:

En cuanto a los himnos es mejor leer el libro de Juan Sebastián intitulado Espejo de sacerdotes... véase... a Molina, el Cartujano, en su Instrucción de Sacerdotes... y se entienden muy bien en los hechos por Marín o Piferrer, poco variados toca el M. R. P. Bartolomé de Letona, en la vida de la Madre Jerónima de la Asunción, que intitula: La perfecta religiosa, libro dos, cap[ítulo] dos, desde el número catorce, y las meditaciones en el capítulo veinte y uno y los ofrecimientos en el soliloquio treinta del mismo lugar. ${ }^{11}$

Al decir Marín o Piferrer, Núñez de Miranda cita las ediciones del siglo XVII del impresor madrileño Pedro Marín y del barcelonés Juan Piferrer; por su parte, al señalar la vida de la madre Jerónima de la Asunción de Bartolomé de Letona, se refiere a la Perfecta religiosa, impresa en Puebla en el taller de la viuda de Juan de Borja en 1662.

En lo que respecta a las imágenes para Núñez de Miranda no son tan valiosas como la lectura, pese a eso sólo hace una referencia al comentar «si pudieras leer la Practica de los ejercicios de San Ignacio del P. Sebastián será lo mejor, porque sus grabaditos son claros, la explicación sencilla y la enseñanza valiosa». ${ }^{12} \mathrm{La}$ obra a la que hace alusión es Práctica de los ejercicios espirituales del jesuita Sebastián Izquierdo impresa en Puebla por Diego Fernández de León en 1685

Núñez de Miranda con su libro Distribución de las obras ordinarias... presenta y desarrolla todo lo que debe tener, saber y poseer la perfecta religiosa. En lo que toca a los libros, alude a setenta y tres, que divide en tres secciones: espiritualidad, devoción y liturgia. El contenido en cada sección es en espirituales (27 títulos) se hallan ejercicios, formación, meditaciones, hagiografías, biografías y crónicas. ${ }^{13}$ En devoción (30 títulos) están catecismos,

\footnotetext{
${ }^{10}$ Núñez, Distribución..., p. 91

${ }^{11}$ Núñez, Distribución..., pp. 76-8

${ }^{12}$ Núñez, Distribución..., p. 83

13 Cabe señalar que los espirituales los subdivide en recreación, instrucción y provecho espiritual.
}

Titivillus, ISSN 2387-0915, ISSN-e 2603-9966, 1 (2015), pp. 295-303 
doctrinas, vidas de santos, panegíricos, sermones, reglas y constituciones de la orden. En litúrgicos (16 títulos) se encuentran ceremoniales, misales, devocionarios y breviarios.

Las obras y los autores más referidos son los siguientes: Contempus mundis de Tomás de Kempis, O. S. A. con quince citas; Obras completas de Juan Eusebio Nieremberg, S. J., de Santa Teresa de Jesús y de Juan de Ávila, con siete citas cada uno; El Catecismo y exposición breve de la doctrina cristiana del padre Jerónimo de Ripalda, S. J., los Avisos espirituales de Alonso de Andrade, S. J. y las Meditaciones espirituales de Luis de la Puente, S. J. con seis citas cada uno; La perfecta religiosa de Bartolomé de Letona, O.S.F.; Los ejercicios de perfección y virtudes cristianas de Alonso Rodríguez S. J.; las Obras espirituales de Juan Falconi, S. J. y la Práctica de los ejercicios espirituales de Sebastián Izquierdo, S. J. con cinco citas cada uno. Cronológicamente existen ediciones del siglo XVI, siendo superior la producción del XVIII, los autores en un noventa por ciento son jesuitas y en su mayoría los libros proceden de talleres españoles o reediciones mexicanas. Los formatos que maneja son el octavo en un ochenta por ciento, seguido del cuarto, el dieciseisavo y el folio.

Pero de esta realidad planteada por el máximo confesor en la Nueva España qué se empleó en los acervos femeninos. Las respuestas son que todas y cada una de las obras citadas se hallan en los acervos bibliográficos del Convento de San José de Gracias de la ciudad de México; del Colegio San Ignacio de Loyola de las Vizcaínas, en los Conventos de las Dominicas de Puebla y Morelia; así como en el Convento de Nuestro Señor de San José y de Santa Teresa de Jesús de las Carmelitas Descalzas de Puebla, en los que además existen por lo menos dos ejemplares de la obra Distribución de las obras ordinarias... de Antonio Núñez y de otros títulos, sobresaliendo Cartilla de la doctrina religiosa.

La organización temática de los libros; esta es: espirituales, devoción y litúrgicos, que explaye Núñez de Miranda en su obra es el esquema de organización que hallamos en el inventario ${ }^{14}$ de los libros que contiene la Biblioteca del Convento de San José de las Carmelitas Descalzas de Puebla de 1835, en el cual sólo hacen un cambio en el rubro Devoción, pues ponen los libros de sus fundadores antes de los sermones y después de las reglas y constituciones, por lo demás es exactamente igual incluso en la presentación de los nombres de los autores.

Otros datos que concuerdan con la obra de Núñez de Miranda son las lenguas, ya que de los cinco acervos trabajados que arrojan 3,066 volúmenes, 2,641 están escritos en español y 425 en latín. Los escritores es otra coincidencia, debido a que 2,352 son jesuitas; 298 dominicos; 210 carmelitas y

${ }^{14} \mathrm{El}$ título completo es: Inventario de los libros que contienen los dos estantes de la librería del Convento de Nuestro Padre Señor San José y Nuestra Madre Santa Tersa Antiguo de Carmelitas Descalias de la ciudad de los Ángeles y primero de América. Año de 1835 siendo actual prelada Nuestra Muy Reverenda Madre Isabel de la Encarnación y librera la hermana Ángela del Señor San José. 
86 pertenecen a otras órdenes. Entre los autores se hallan en los primeros lugares Jean Croiset; Alonso Rodríguez; Juan Eusebio Nieremberg; Antonio Arbiol; Alonso de Andrade, Luis de Granada; santa Teresa de Jesús; Antonio Núñez de Miranda y María de Jesús de Agreda.

Las palabras que abundan en los títulos son: ejercicios, meditación, enseñanza, vida, mística, alma, camino y año. De acuerdo al lenguaje empleado es claro que en los 3,066 libros analizados 1,850 están dirigidos a un lector femenino, 861 masculino y 355 general; aquí los vocablos que predominan son: religiosa y esposa.

Cabe señalar que la adquisición de los libros por parte de los conventos y de colegios femeninos en la Nueva España no era por la compra directa, sino a través de su confesor o bien con el permiso del obispo, así se aprecia en los ex libris manuscritos que, en su mayoría, dicen "este libro me lo dio mi confesor" o bien "por obsequio y con la licencia del sr. Obispo"; por ello, llama la atención que 2,325 obras son primeras ediciones; mientras que 485 segunda y 256 llegan hasta la quinta. De ellas 702 son reimpresiones que en su mayoría las hicieron talleres de la ciudad de México tomando como originales las realizadas en España, específicamente en Madrid, Valencia, Salamanca y Zaragoza, el tema principal de estos libros son las reglas y constituciones, así como los ejercicios espirituales de San Ignacio de Loyola.

Por otro lado, los países de donde proceden los ejemplares son España con 1454 obras, México con 1,130; Italia con 258; Francia con 151; Bélgica con 41, Alemania con 22 y 10 de Portugal. Esto es el consumo de libros proviene un setenta por ciento de Europa y sólo un 30 por ciento de México. Las principales ciudades de producción son Madrid, México, Barcelona, París, Puebla, Sevilla, Roma y Zaragoza. Entre los 467 impresores que existen sobresales de Europa la Imprenta Real de España, Joaquín Ibarra, Benito Cano y Antonio de Sancha; de México José de Jauregui, Bernardo de Hogal, el Seminario Palafoxiano y María de Rivera, entre otros.

De los 3,066 libros 1,722 fueron editados en el siglo XVIII, 893 en el XVII, 1 en el XVI y 450 en el XIX, otra coincidencia con Núñez de Miranda que se une con la de los formatos, pues 1,661 son octavo; 978 cuarto; 200 folio, 131 diez y seisavo y 96 treinta y dozavo. De todos ellos, sólo 850 están ilustrados, pero cada grabado hace alusión a la lectora, porque ella es presentada como poseedora de libros, como tema principal de la obra y como un ente participativo.

Los textos tienen como fin ser auxiliares o guías para instrucción. Es por ello, que se halla una la literatura pedagógica que desarrolla conceptos para hacer ligero el mensaje escrito y que, como método, utiliza el diálogo entre maestro y pupila.

La temática es otra casualidad ya que de los 24 rubros existentes en los cinco acervos 1,603 versan sobre espiritualidad, 964 sobre devoción y 499 sobre liturgia. Por otro lado, aunque Núñez de Miranda no lo comenta, nos parece conveniente mencionar que en 2,358 ejemplares su encuadernación es 
en pergamino; 650 en piel y 58 en cartón; de ellos 16 se hallan expurgados por el poseedor en el texto, 14 pertenecen al siglo XVIII y 2 al XVII; 15 son de origen español y 1 mexicano. Finalmente, la marca de propiedad más empleada es el ex libris manuscrito en el que se anuncia que se tiene licencia para leerlo y enseguida se anota el nombre de la lectora. En segundo lugar encontramos la marca de fuego, pero sólo de los Conventos de las Dominicas, de San José de Gracia y de las Carmelitas de Puebla.

Con esta información es lícito pensar que obras como Distribución de las obras ordinarias y extraordinarias... de Antonio Núñez de Miranda nos permite comprender el universo intelectual en el que se formaban las mujeres novohispanas, los libros que empleaban y su valor en su instrucción. Asimismo, que, a diferencia de los acervos dedicados a la formación masculina, en donde ahondan los impresos venecianos, flamencos, españoles y alemanes; las bibliotecas femeninas se inclinan por las producciones españolas y novohispanas, cuyas lectoras tuvieron que esperar más de un siglo para poseer acervos propios, que representaban el cuerpo místico con el que aprendía y cuyos preceptos llevaban en su alma toda su vida. 